\title{
REDISCUTINDO PATRIMONIALIDADE AMBIENTAL A PARTIR DE UMA PESQUISA EM EDUCAÇÃO DO CAMPO
}

\author{
Claudionor Renato da Silva ${ }^{1}$ \\ Vera Lúcia Silveira Botta Ferrante ${ }^{2}$
}

\section{RESUMO}

Patrimonialidade ambiental é um conceito em construção nos estudos do NUPEDOR, desde 2009, em que se vem pensando a possibilidade deste conceito se traduzir como um modelo de gestão ambiental nos assentamentos, perpassado pela educação. O objetivo deste artigo é rediscutir patrimonialidade ambiental a partir da política educacional do campo com dados e reflexões de uma pesquisa na área da educação. Com a utilização do método bibliográfico na perspectiva de análise de um marco referencial lançando hipóteses de aproximação teórica e avançando a produção do conhecimento na temática são levantadas duas rediscussões fundamentais, atualizando o conceito de patrimonialidade ambiental: a primeira trata das contribuições dos estudos sobre novas ruralidades; a segunda rediscussão do conceito de patrimonialidade vem da análise documental do Projeto Político Pedagógico de uma escola do campo em que a temática da sustentabilidade na educação contribui para se repensar o meio ambiente como patrimônio, perpassando as políticas públicas tanto educacionais quanto de desenvolvimento dos assentamentos rurais.

Palavras-chave: Patrimonialidade Ambiental. Educação do Campo. Assentamentos.

\footnotetext{
${ }^{1}$ Universidade Federal do Tocantins (UFT) crenato@uft.edu.br

${ }^{2}$ Programa de Pós-Graduação em Desenvolvimento Territorial e Meio Ambiente, Centro Universitário de Araraquara (UNIARA)
} 


\title{
REVISITING ENVIRONMENTAL PATRIMONIALITY FROM A RESEARCH IN THE COUNTRYSIDE EDUCATION
}

\begin{abstract}
Environmental Patrimoniality is a concept in construction in NUPEDOR studies, since 2009, in which it has been considered the possibility of this concept to be translated as a model of environmental management in the settlements, permeated by education. The purpose of this article is to revisit environmental patrimoniality from the field educational policy using data and reflections of a research in education. Using the literature method in the analysis perspective of a reference point launching chances of theoretical approach and advancing the production of knowledge in the subject, two fundamental rediscussions, updating the concept of environmental patrimoniality, are raised: the first deals with the contributions of studies on new ruralities ; the second rediscussion of the concept of patrimoniality comes from the documentary analysis of the Pedagogical Political Project of a field school where the issue of sustainability in education contributes to rethinking the environment as a heritage, passing both educational public policies and the development of rural settlements.
\end{abstract}

Keywords: Environmental Patrimoniality. Countryside Education. Settlements.

\section{INTRODUÇÃO}

O presente trabalho retoma artigos sobre Patrimonialidade Ambiental (Silva; Ferrante, 2009a, 2009b, 2010) em que se buscava uma aproximação teórica entre a gestão ambiental em assentamentos rurais (política pública) e a realidade desta gestão nestes espaços, tendo como base empírica, dados coletados, numa ampla pesquisa produzida pelo NUPEDOR, financiado pelo CNPq, no período de 2007 a 2010, sob o título "Assentamentos e desenvolvimento: bloqueios, tensões e perspectivas (uma análise comparativa entre regiões diferenciadas)".

Patrimonialidade ambiental é pensada na perspectiva da gestão e tem seus primórdios de produção, no âmbito internacional, no artigo de Garret Hardim, a Tragédia dos Comuns, publicado em 1968.

\footnotetext{
Essa gestão patrimonial perpassa a consideração da “[...] diversidade de representações cognitivas dos atores sociais em jogo, a variabilidade envolvida nas diferentes escalas espaciais (do local ao global" e temporais (do curto ao longo prazos) [...]. Portanto, o enfoque patrimonial aplicado ao meio ambiente vai destacar a "dimensão da base transmissível (material e imaterial) dos processos de desenvolvimento [...] aliando o problema ambiental às buscas por soluções negociadas envolvendo o conjunto dos atores sociais implicados num contexto de reflexões amplas" [...] (SILVA; FERRANTE, 2009b, p. 69).
}

A dimensão educacional já estava implícita no artigo no artigo de 2009, conforme a citação acima. Ela é reforçada, ao final do trabalho:

[...] a escola tem um papel fundamental no processo dessa construção coletiva que não é apenas perceptivo, mas envolve muitos outros aspectos, inclusive e principalmente, o retorno dos assentados para os movimentos e as lutas do princípio da conquista da terra, o revigoramento do sentimento de pertencimento (SILVA; FERRANTE, 2009b, p. 84). 
Ao se rediscutir neste momento a abordagem da Patrimonialidade Ambiental, pelo método bibliográfico, é trazido à reflexão os resultados da dissertação "Formação ambiental na escola do campo" (Silva, 2011), apresentando duas importantes contribuições deste estudo, que permitem o avanço do conhecimento da abordagem da Patrimonialidade Ambiental, tendo como aporte, as políticas públicas tanto educacionais quanto de gestão dos assentamentos, quais sejam: (1) o tema das novas ruralidades e a questão ambiental: políticas e pesquisas; (2) o Projeto Pedagógico de uma escola do campo: políticas e currículo com focos na sustentabilidade e na Reforma Agrária.

Algumas problematizações: que discursos das políticas educacionais do campo (assentamentos rurais) aproximam-se do conceito de patrimonialidade ambiental? Nessa aproximação possível, que contribuições os estudos da patrimonialidade ambiental podem fornecer à educação?

As seções da parte introdutória deste artigo tratam, em primeiro lugar das políticas educacionais para o campo e a relação Educação do Campo/Meio Ambiente. A seção sobre o método bibliográfico em Sampieri; Collado; Lucio (2006) explicita além de algumas considerações sobre o método, também os procedimentos da pesquisa. Em Resultados e Discussão se assinala as rediscussões da abordagem da Patrimonialidade Ambiental nos diálogos de uma pesquisa em educação do campo (SILVA, 2011).

\section{Políticas educacionais para o campo}

As políticas educacionais para o campo são tardias no Estado brasileiro, se considerados os diversos momentos históricos da educação. Tais políticas caracterizam-se pela governabilidade, uma vez que se trata de uma política abrangente direcionada pelo federalismo (ARROYO; CALDART; MOLINA, 2004; SHIROMA; MORAES; EVANGELISTA; 2007; SOUZA, 2008).

Outra característica que singulariza as políticas para o campo (Souza, 2008) é que a ação de governança do Estado não se faz ou não se dá, senão pelo movimento dos grupos interessados, portanto "de baixo para cima".

No caso dos assentamentos rurais, o Movimento dos Trabalhadores Rurais Sem-Terra (MST) é responsável não só por reivindicar do Estado brasileiro uma educação para o campo, como também organizar um currículo educacional.

O Estado, por sua vez, ao elaborar o currículo, atendendo às reinvidicações dos movimentos, assume para si, a governança, a elaboração, enfim, mostra-se benfeitor, procurando o campo de forças no qual se insere a problemática de educação do campo. A LDBEN (Lei de Diretrizes e Bases da Educação Nacional, 9394/96) traz a educação do Campo como legislação educacional com o seguinte texto.

Art. 28. Na oferta de educação básica para a população rural, os sistemas de ensino promoverão as adaptações necessárias à sua adequação às peculiaridades da vida rural e de cada região, especialmente: I - conteúdos curriculares e metodologias apropriadas às reais necessidades e interesses dos alunos da zona rural; II organização escolar própria, incluindo adequação do calendário escolar às fases do ciclo agrícola e às condições climáticas; III - adequação à natureza do trabalho na zona rural.

A partir da LDBEN, Resoluções e outros documentos do MEC são emitidos, assegurando, assim, uma educação do campo. Dentre essas políticas podemos citar: Parecer CEB n 36/2001; Resolução CEB n ${ }^{\circ}$ 01/2002 que institui as Diretrizes Operacionais para a Educação Básica nas Escolas do Campo; Parecer CEB 01/2006 que Recomenda a Adoção da Pedagogia da Alternância em Escolas do Campo; Diretrizes Complementares CNE/CEB Resolução n 2, de 28 de abril de 2008.

A Resolução Nº 01/02 CNE/CEB, de 03 de abril de 2002, explicita a articulação do currículo da escola 
do campo com a temática ambiental:

Artigo $4^{\circ} \mathrm{O}$ projeto institucional das escolas do campo (...) constituir-se-á num espaço público de investigação e articulação de experiências e estudos direcionados para o mundo do trabalho, bem como para o desenvolvimento social, economicamente justo e ecologicamente sustentável (BRASIL, 2002).

Ser um espaço de investigação constitui-se, primeiramente, em ser um espaço, onde as questões postas, dentre elas, o desenvolvimento social na dimensão ecológico-sustentável estejam presentes. Supõe-se, portanto, que o Projeto Político Pedagógico da Escola do Campo, prime por essa dimensão no currículo: a dimensão do meio ambiente e toda a amplitude da temática, como por exemplo, ecologia, sustentabilidade, desenvolvimento ambiental, direito ambiental.

\section{Educação do campo, Meio ambiente.}

A expressão "campo" é definida por Fernandes (2004) como:

(...) lugar de vida, onde as pessoas podem morar, trabalhar, estudar com dignidade de quem tem o seu lugar, a sua identidade cultural. O campo não é só o lugar da produção agropecuária e agroindustrial, do latifúndio e da grilagem de terra. O campo é espaço e território dos camponeses e dos quilombolas (...). (FERNANDES, 2004, p. 137).

Esse termo assumido pelo movimento de educação para o campo tem uma ligação direta com o meio ambiente, dada a essência da prática social que é característica da educação e, propriamente, do pensamento educacional originário no MST, bem como dos assentamentos rurais, como bem mostraram os trabalhos de Arroyo (1989) e Caldart (2000). Uma educação em que o meio ambiente, as preocupações ambientais, estão presentes "na busca por uma educação pública que valorize a identidade e a cultura dos povos do campo, numa perspectiva de formação humana e de desenvolvimento local sustentável (SOUZA, 2008, p. 1098)".

A Educação do Campo, assim, tem como uma das suas prerrogativas fundamentais, a educação de crianças e adolescentes, visando a sustentabilidade e o desenvolvimento dos assentamentos rurais (ARROYO; CALDART; MOLINA, 2004; BRASIL, 2007)

Brasil (2003) assevera a formação dos sujeitos do campo, os educandos e está atrelada ao desenvolvimento sustentável dos espaços rurais:

Políticas de educação como formação humana pautam-se pela necessidade de estimular os sujeitos da educação pela sua capacidade de criar com outros um espaço humano de convivência social desejável. A formação humana é todo o processo educativo que possibilita ao sujeito se constituir enquanto ser social responsável e livre capaz de refletir sobre sua atividade e seu refletir, capaz de ver e corrigir os erros, capaz de cooperar e de possuir um comportamento ético, porque não desaparece em suas relações com os outros. Portanto, a educação como formação humana é também uma ação cultural. A educação como estratégia fundamental para o desenvolvimento sustentável do campo deve se constituir nas políticas públicas como uma ação cultural comprometida com o projeto de reinvenção do campo brasileiro (BRASIL, 2003, p.34).

Assim, a dimensão ambiental na educação do campo vai além de uma prerrogativa curricular: questões referentes à terra, à reforma agrária - daí a instigação e aproximação aos estudos sobre patrimonialidade ambiental (SILVA; FERRANTE, 2009a, 2009b, 2010). 


\section{METODOLOGIA}

O método bibliográfico - opção deste trabalho - como propõem Sampieri; Collado; Lucio (2006) insere-se numa perspectiva de marco teórico que implica nas funções de servir de marco de referência, estabelecer hipóteses, ampliar o horizonte, orientar o estudo e prevenir erros.

Ao se rediscutir o conceito de patrimonialidade ambiental (Silva; Ferrante, 2009) com o método bibliográfico pretende-se pelo menos duas funções: recolocar um marco de referência, estabelecer novas hipóteses e aproximações e ampliar o horizonte temático.

Para os autores

[...] é sempre importante revisitar o passado para construir o presente e visualizar o futuro, ou seja, é conveniente localizar, obter e consultar estudos anteriores, livros, revistas científicas, ensaios, teses, fóruns e páginas da Internet, material audiovisual, testemunhos de especialistas e toda fonte que se relacione com o problema ou tema de pesquisa [...]. Uma vez formulado o problema de estudo [...] e quando já foram avaliadas sua relevância e viabilidade, o passo seguinte consiste em sustentar teoricamente o estudo [...]. Isto implica analisar e expor as teorias, os enfoques teóricos, as pesquisas e os antecedentes em geral, considerados válidos para o correto enquadramento do estudo [...] (Sampieri; Collado; Lucio, 2006, p. 52).

Partindo, assim, "[...] de uma perspectiva teórica ou de referência (Sampieri; Collado, Lucio, 2006)", neste caso, a perspectiva da patrimonialidade ambiental, busca-se avançar na produção do conhecimento em um estudo posterior numa escola de educação do campo (Silva, 2011) rediscutindo assim o referencial em estudo com foco nas questões ambientais, nos assentamentos de reforma agrária.

\section{RESULTADOS E DISCUSSÃO}

\section{Patrimonialidade ambiental: um conceito ainda em construção}

Discutiu-se em trabalhos anteriores (Silva; Ferrante, 2009 a, 2009 b, 2010) que o conceito da patrimonialidade ambiental (Vieira; Weber, 2000) advém de uma perspectiva de gestão. Um instrumento de gestão para a recuperação de áreas degradadas, na experiência francesa, em que um conjunto de ações como o de alteração da paisagem e de recuperação do espaço geográfico foram tomadas com vista à preservação do que restou com a ocupação humana no crescimento das cidades e a retomada ou recuperação do "verde" original.

Bem comum. Essa é a designação chave para se entender e conceituar patrimonialidade. A natureza, os bens naturais, os espaços e lugares como existência e "propriedade comum". $\mathrm{O}$ ator social na relação com o meio - ator ou atores sociais, entendidos aqui como os sujeitos pertencentes ao território e em vivência comum. Implica também (Silva; Ferrante, 2009b) na maneira como esse ator age sobre e com esse meio e, também, na ação reversa, como o meio atua com e sobre esse ator. Esse conjunto e dinamismo de ações e relações é que definem a noção de patrimônio relacionado ao meio ambiente, como:

O conjunto de elementos materiais e imateriais que concorrem para a manutenção e o desenvolvimento da identidade e da autonomia de seu titular no tempo e no espaço, através do processo de adaptação a um meio evolutivo (OLLAGNON, 2000, p. 183).

Na patrimonialidade, há entre o homem e o espaço (o lugar) uma relação sistêmica ou ecossocioecológica - como define Capra (1996) - "relações ecossistêmicas" de equilíbrio, acomodação e resistências. Ademais, essa relação (ou relações) operacionaliza a identidade do sujeito. Nos assentamentos rurais, o sujeito 
do campo, envolto em uma trama de tensões na qual o fazem presentes os gestores, os dirigentes de movimentos associados à luta pela terra, os representantes do poder local, dentre outros.

Pensou-se, então que um dos caminhos para o entendimento da patrimonialidade ambiental era a gestão, a gestão administrativa dos assentamentos rurais, para os quais, uma ação educativa formal e não formal eram imprescindíveis (SILVA e FERRANTE, 2009b).

Utilizou-se a categoria "gestão" dos assentamentos como foco de ação da patrimonialidade ambiental como um conjunto de ações dos órgãos institucionais administrativos (assistência técnica, unidades de saúde, instituição escolar) e dos assentados, evidentemente, atores do processo. Ações em parceria, na coletividade. Acesso, uso, recuperação/preservação/conservação. E, nesse sentido, ações mais voltadas à recuperação dos espaços dos assentamentos, com acesso e uso no enfoque estratégico patrimonial conforme propõe Ollagnon (2000).

Nesta proposta de gestão para os assentamentos, adotou-se a definição de gestão interdisciplinar, já que, no modelo francês de patrimonialidade ambiental, a gestão se dava com a ação de uma equipe inter e multi disciplinar. Conceitua-se gestão interdisciplinar como:

(...) ato de gerir, gerenciar, gestionar, administrar... O ato da "gestão interdisciplinar" sempre envolve pessoas (capital intelectual e mão de obra, stakeholders etc.), processos (atividades ou funções) e recursos pertinentes a diversas formas conjuntas e organicamente interligadas, ou seja, em redes, respeitando-se as diversidades. O termo "gestão" na era do conhecimento e da informação no mundo global será aqui abordado como diretrizes multidisciplinares e atividades correlatas e o gerenciamento dos recursos naturais e energia e como tarefa multidisciplinar que associa pessoas, administração, tecnologia e organizações, bem como todos os desempenhos operacionais relacionados ao modo de empreender melhor o uso dos fatores energia, recursos natural, processo, etc., com a finalidade de permitir um aprimorado desempenho socioambiental desses fatores (RODRIGUES; SANTANA; BERNABÉ., 2007, p. 209).

Na associação “de pessoas, administração, tecnologia e organização” têm-se, portanto, uma perspectiva educativa do que podemos chamar de Educação Patrimonial Ambiental, da qual a escola e a ação dos órgãos gestores dos assentamentos podem se tornar foco dessa ação gestora integrada de patrimonialidade ambiental.

Esse novo modelo de gestão (patrimonial ambiental) supõe uma gestão social dos diversos atores envolvidos (os segmentos racionais) numa função de intencionalidade de consenso e globalizadora, mas também caracterizada "através das arbitragens e negociações dos atores situados num contexto de resolução de problemas (...) de todo um comportamento efetivo do ator e do "sistema de ação" (OLLAGNON, 2000, p. 176, grifos meus).

Trata-se, conforme Ollagnon (2000):

- do desenvolvimento de uma consciência patrimonial dos atores implicados e do sistema de ação;

- da instauração de uma relação patrimonial;

- do firmamento de negociação e operacionalização entre os atores para localização/identificação de interesses patrimoniais comuns.

Consciência relação e interesses patrimoniais comuns promovem fonte primária de conhecimento e enriquecimento individual e coletivo, o que pode ocorrer de maneira mais incisiva nos espaços dos assentamentos rurais. Pontuam-se então, meios de comunicação formal e/ou informal que possam assegurar uma Educação Patrimonial Ambiental na comunidade de ação (o assentamento) que sejam:

Locais físicos e institucionais de encontro, de comunicação, de negociação e de gestão objetivando minimizar a gestão direta e maximizar a negociação; linguagens de gestão e de negociação adaptadas e aceitas, específicas para cada comunidade de ação e centradas num problema e procedimentos de gestão e negociação (OLLAGNON, 2000, p.192). 


\title{
Rediscussão do conceito: contribuições dos estudos das novas ruralidades
}

No estudo de Silva (2011) observa-se que os estudos das novas ruralidades trazem contribuições ao conceito de patrimonialidade ambiental, tanto em relação à gestão dos assentamentos, como também, às expectativas de educação formuladas pelas políticas educacionais para o campo.

\begin{abstract}
Ancorados pelos procedimentos de uma pesquisa interpretativa com amplas bases na filosofia e na antropologia, autores internacionais, provenientes principalmente do campo da Sociologia, como (...) Mormont (1989, 1997) forneceram novas perspectivas para o uso teórico das expressões "rural" e "ruralidade", ao mesmo tempo em que, direta ou indiretamente, redefiniram "urbano". No Brasil, os principais pesquisadores que absorveram tais contribuições foram a antropóloga Maria José Carneiro (1998, 2003), ao tratar das ruralidades (...). Paralelamente, ancorado pelas críticas da ciência e da modernidade, Roberto Moreira (2002, 2006) vem promovendo a rediscussão das categorias rural e ruralidade por meio de abordagem profundamente interdisciplinar, voltada à desnaturalização destas e de outras expressões. Sua reflexão se destaca por vincular as disputas de poder à produção de significados para certos "rural" e "urbano" construídos pelos diferentes agentes sociais (BIAZZO, 2008, p. 134, grifos meus).
\end{abstract}

Nos estudos atuais dessa nova ruralidade, as reflexões se pautam em um rural, cuja análise incorpora o ambiental. Para Marc Mormont, um rural inclui reflexões do ambiental e seus sujeitos.

Segundo Souza; Brandenburg (2009) para Marc Mormont "o meio ambiente é um modelo de referência para pensar a ruralidade contemporânea" (SOUZA E BRANDENBURG , 2009, p.3).

Esta interpretação de Marc Mormont parte do que vem a ser meio ambiente para ele:

O meio ambiente é antes de tudo um território: ele é não somente uma força produtiva, mas também a base das identidades locais e regionais que podem sustentar os projetos de desenvolvimento e as dinâmicas locais (...) constitui um modelo de referência para pensar a ruralidade contemporânea: as relações entre o rural e urbano, mas também a diversidade de atores, de usos, de saberes, de representações e técnicas a partir de diferentes campos (SOUZA; BRANDENBURG , 2009, p. 3).

Esse é um dos pressupostos fundamentais dos estudos das novas ruralidades. Schneider (2009) elenca dez dimensões do rural globalizado ("rural global") e nestas, o ambiental está elencado nos itens f e g, conforme destaques no texto:

a) a ruralidade globalizada se caracteriza por redes internacionais de commodities; b) a ruralidade globalizada é dominada por grandes corporações transnacionais que organizam as relações e as interações econômicas e comerciais; c) a ruralidade globalizada também é caracterizada por fluxos de migrantes e trabalhadores em diferentes tipos de setores, em geral em condições de vulnerabilidade; d) o rural globalizado é amplamente utilizado por não-agricultores, especialmente turistas, que são crescentemente atraídos pelas amenidades e paisagens; e) a ruralidade globalizada atrai capitais internacionais que procuram as áreas rurais como espaços para construção civil e habitação, especialmente nas zonas que possuem vantagens naturais e locacionais; f) a ruralidade global recebe forte suporte discursivo por meio da crescente defesa da natureza e das críticas contra a degradação ambiental; g) mesmo assim, a ruralidade global é fortemente afetada pelos impactos ambientais, sobretudo pela destruição florestal, poluição das águas e comprometimento das paisagens; h) a ruralidade globalidade é polarizada por grandes e pequenos empreendedores, opondo as corporações internacionais aos pequenos proprietários e camponeses; i) a ruralidade global possui espaços de luta política globais que superam os Estados nacionais, as regiões e localidades, tal como o caso das negociações que ocorrem no âmbito da OMC; j) mas, a ruralidade globalizada também continua a ser um espaço de contestação, embora a forma da ação política e os seus alvos tenham se alterado (SCHNEIDER, 2009, p.10). 
Pensando essas dez categorizações/dimensões do novo rural, particularmente voltada à questão ambiental, Schneider (2009) nos remete aos estudos de Marc Mormont. Segundo o autor, Marc Mormont:

(...) apresenta a hipótese de que em face das transformações que afetaram os espaços rurais durante o processo de modernização, já não faz sentido buscar uma definição empírica do rural ou da ruralidade. Segundo este autor, a diferença entre o rural e o urbano já não pode ser encontrada nas formas de produção ou da ocupação da força de trabalho, nem nos processos de mobilidade social. Neste sentido, sugere que a forma de distinguir o rural e lhe dar uma definição própria seria através da compreensão da diversidade de identidades dos atores que usam e habitam no rural, que já não são apenas os agricultores. Portanto, o rural passaria a ser uma categoria identificável a partir do modo como seus atores constroem sua relação e suas representações simbólicas com o espaço. A ruralidade torna-se uma categoria social e espacial que pode ser apreendida através das representações dos indivíduos, através da sua identidade social (...)Sendo o espaço rural ocupado e usado por vários atores (turistas, ambientalistas, interessados na preservação do patrimônio, esportistas, ex-residentes), inclusive os agricultores, torna-se necessário buscar uma definição que leva em consideração a heterogeneidade de sentidos que cada um destes atores e grupos atribui ao rural. Isto remete à análise das construções mentais que os atores e agentes estabelecem em relação ao rural, o que dá início a um conjunto de estudos sobre vida cotidiana e como a ruralidade é vivenciada na cotidianidade (SCHNEIDER, 2009, p.13-14).

As contribuições de P. Perrier-Cornet, segundo Souza; Brandenburg (2009), para a compreensão da nova ruralidade, permeada pela dimensão ambiental, estão no seu estudo, sobre a noção de patrimonialização, temática que vem sendo estudada por Silva; Ferrante (2009a, 2009b, 2010).

Patrimonialização para P. Perrier-Cornet não é sinônimo de privativo, mas de acesso livre, regulação para exploração, uso consciente e perspectiva presente e futura. O rural para P. Perrier-Cornet (Souza e Brandenburg, 2009) tem a tríplice configuração de recurso, quadro de vida e natureza: recurso, enquanto espaço de produção (trabalho e subsistência); quadro de vida; como o lugar da vida, da existência e, a natureza, onde se dão as relações e existências ecossistêmicas ou relações ecológicas. Souza e Brandenburg (2009) acrescentam que:

Um detalhe importante, conforme lembra ainda Perrier-Cornet (2002), é que as três figuras acima estão profundamente imbricadas, que elas são interdependentes e, com frequência, são concorrentes, visto que elas "utilizam" o mesmo espaço e os mesmos recursos. Fundamentalmente, elas estão em "tensão" (SOUZA e BRANDENBURG, 2009, p. 9).

Jollivet e Pavê (2000) destacam o fator ecológico na temática do "novo rural":

A de um rural formado, permeado, estruturado, dinamizado, mesmo de forma conflituosa, pela referência ambiental e pelo projeto e sentido que esta referência veicula... Seja pela ideia de uma agricultura sustentável, seja por uma nova concepção de arte de morar no espaço de trabalho e no espaço doméstico - uma nova forma de tratar e gerir uma natureza próxima e cotidiana, uma nova maneira de apreciar as amenidades que ela traz (JOLLIVET E PAVÊ, 2000, p.365).

O aspecto da agricultura sustentável já é um tema recorrente nos estudos da sociologia rural. Uma referência importante, dentre outras é Ehlers (1996). Jollivet; Pavê (2000) indicando um itinerário de pesquisa na relação meio ambiente/sociedade, propõem uma ênfase nas seguintes vertentes que pensamos serem apropriadas para os estudos nos assentamentos rurais:

- descoberta e compreensão daquilo que se transforma no ambiente por conta das ações humanas;

- um esforço na divulgação e na luta pela denúncia quanto aos perigos à natureza, tanto local, quanto global que podem afetar a sociedade e os indivíduos, relacionando, fundamentalmente, meio 
ambiente e saúde;

- pesquisas e proposições de alternativas para solução de problemas ambientais.

\section{Rediscussão do conceito: na prática, contribuições do Projeto Pedagógico de uma Escola do Campo.}

O Quadro 1, apresenta as palavras-chave do Projeto Pedagógico de uma escola do campo, investigada na dissertação de Silva (2011).

Quadro 1: Palavras-chave do Projeto Político Pedagógico.

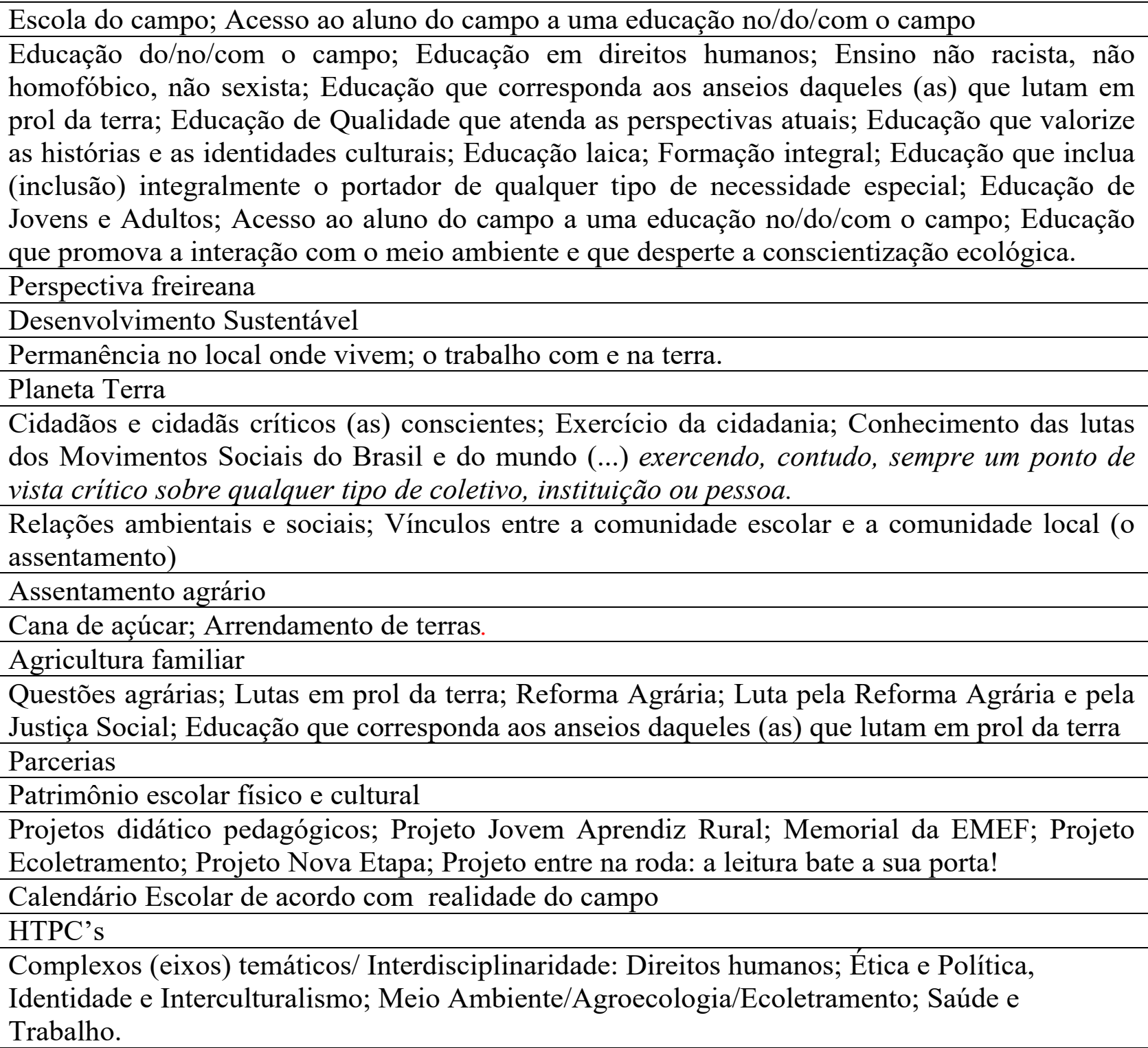

FONTE: Silva (2011). 
No Projeto Político Pedagógico o ideal de educação apoia-se na pedagogia de Paulo Freire, que se articula à questão da terra, da reforma agrária.

A reforma agrária não é uma questão simplesmente técnica. Envolve, sobretudo, uma decisão política, que é a que efetua e impulsiona as proposições técnicas que, não sendo neutras, implicitam a opção ideológica (...) A reforma agrária deve ser um processo de desenvolvimento do qual resulte necessariamente a modernização de campo, com a modernização da agricultura (...) em última análise, a reforma agrária, como um processo global, não pode limitar-se à ação unilateral no domínio das técnicas de produção, de comercialização etc., mas pelo contrário, deve unir este esforço indispensável: o da transformação cultural, intencional, sistematizada, programada. Nesse sentido, o assentamento (...) deve ser também, todo ele, uma unidade pedagógica na acepção ampla do termo (SOUZA et al., 2001, p. 307, 308, 309).

Educação relaciona-se ao trabalho na e com a terra - portanto, próximo, muito próximo à política educacional (LDBEN). A interligação da escola com o assentamento e com a questão agrária, enquanto discurso, está evidente na introdução do documento:

(...) A escola (...) foi fundada em 1999, fruto da reivindicação dos (as) moradores (as) do local. As terras do (...) foram destinadas ao assentamento agrário. Desde então, os moradores cultivaram mandioca, mamona, feijão de porco, eucalipto, criaram gado, hoje, em grande parte dos lotes do local há cana de açúcar. Dessa forma, as famílias encontram suas subsistências através do trabalho voltado à agricultura familiar, sendo que mais recentemente alguns assentados (as) arrendaram suas terras às usinas de cana de açúcar para o cultivo dessa cultura. Neste documento manifesta-se o compromisso de desenvolver na escola e com a escola um projeto político e pedagógico, que realmente atente para as questões agrárias (...) e para o desenvolvimento sustentável do Planeta (PROJETO POLÍTICO E PEDAGÓGICO).

Essas discussões, sem dúvida, atreladas ao meio ambiente, à realidade específica do campo têm como pano de fundo as contribuições de Marc Mormont, Philippi Perrier-Cornet, Maria José Carneiro e Roberto Moreira e Vera Ferrante. Tem-se um rural que é também urbano, em que as questões ambientais são inerentes.

O assentamento rural é um espaço em que as questões do meio ambiente, num viés ecológico, devem ser tratadas em suas diversas dimensões. E como nos alerta Whitaker (2009):

\begin{abstract}
Não se pode descartar a questão da natureza, quando se trabalha com temas rurais, seja em Sociologia, seja em Antropologia, seja em qualquer outra área das ciências humanas. O pano de fundo dado pelo meio ambiente é fundamental para compreensão do mundo rural e da ruralidade que, no caso brasileiro é um pouco a raiz de todos nós. A valorização do rural deveria ser também ser fundamental para aqueles preocupados com a sobrevivência do planeta e da humanidade, militam em defesa do meio ambiente e trabalham pela preservação da natureza (ou comungam com essas ideias, ou afirmam apoiá-las) (WHITAKER, 2009, p. 36-37).
\end{abstract}

Na abordagem ambiental, voltada à educação, a sentença Educação que promova a interação com o meio ambiente e que desperte a conscientização ecológica indica uma formação que deve levar em conta, a recuperação e preservação ambientais.

É um caminho possível para se pensar um modelo adaptável de sustentabilidade nos assentamentos rurais, valorizando uma agricultura familiar diversificada, agroecológica e de subsistência, marcados pelo fator ecológico, nas ações dos assentados e na formação escolar dos educandos. Pois, são as pequenas propriedades, segundo Whitaker (2009) o locus para tornar possível práticas sustentáveis integradoras, que em extensão, poderão, a partir de políticas públicas e ações afirmativas, efetuar uma "Reforma Agrária mais abrangente".

Das palavras chave "educação", "reforma agrária" e "meio ambiente" vEm o entendimento da educação 
no e do campo. E é importante assinalar a parte da expressão "educação no campo", pois o entender dessa expressão tem a ver com a "permanência/fixação" do homem no espaço rural. Essa expressão é presente no Projeto Político e Pedagógico e muito estudado na Sociologia Rural.

A proposta educativa de desenvolvimento rural sustentável é pensada nessa fixação do homem rural na terra. O que não significa "obrigação" por ficar, mas a criação de possibilidades de sobrevivência com dignidade e justiça social, profissionalização. Ou, como afirma Paulo Freire, a possibilidade de transformação da realidade. Se a educação do campo cria mecanismos curriculares, não para fixação do educando na terra, mas para aquisição de conhecimentos sociais e ambientais mais amplos, pautados na criticidade e leitura de mundo, então, como justifica Whitaker (2009), o sujeito ecológico do campo não ficará por "pressão", mas por opção e, por ter sido possível a construção de um modo de vida agroecológico, rentável, que não agride a natureza, enfim, que está conectado ao urbano, à ciência e à tecnologia disponíveis.

As prerrogativas do desenvolvimento rural sustentável a serem articuladas à proposta educativa da escola do campo estão na notação do documento quanto a um currículo que atenda a esse modelo, que deve se pautar em Projetos - como o Jovem Aprendiz Rural - ou em práticas que articulem o trabalho da terra com a ciência e tecnologia, voltadas ao cotidiano dos educandos, sempre numa relação rural/ urbana e que dê aos educandos, sujeitos ecológicos rurais, a oportunidade de aquisição dos conhecimentos científicos, sociais, culturais, tecnológicos, políticos e ambientais.

A educação voltada para uma formação ecológica sustentável, constitutiva do discurso do Projeto Político e Pedagógico, é apresentada como uma proposta de um currículo que se volta a práticas da agroecologia, agricultura familiar e relações meio ambiente/assentados vivenciados no contato direto com a natureza, com a terra, com os problemas de degradação e queimadas, bem como com a questão do arrendamento de terras ao agronegócio.

\section{CONCLUSÃO}

A rediscussão do conceito - em construção - de "Patrimonialidade Ambiental” permeia, portanto, uma ideia ou proposta de gestão do espaço rural dos assentamentos e da questão do desenvolvimento e, também, pelo interesse assumido pela escola do campo em atender às políticas educacionais que colocam, como imprescindível ao currículo, as questões ambientais.

Ambas as contribuições aqui expostas têm o seu destaque para o conceito de patrimonialidade ambiental para os assentamentos rurais, especialmente porque repousam sobre o contexto nacional, ou seja, mesmo que o conceito de patrimonialidade tenha partido de experiências francesas de recuperação e preservação ambientais urge um modelo brasileiro de gestão para os assentamentos, do qual, a patrimonialidade é uma perspectiva teórica de análise, ainda em construção.

Silva; Ferrante (2009b) apontavam:

\footnotetext{
Outros espaços de sociabilidade e educação não formal são também propícios ao despertar de todos para o bem comum de que são "donos" e responsáveis diretos pela preservação bem como para com a recuperação daquilo que já foi destruído, degradado. Questões que têm que entrar necessariamente na agenda de pesquisa sobre assentamento e nas ações de intervenção por parte dos poderes públicos, dos agentes políticos de mediação. Sem o enfrentamento das questões ambientais, o futuro dos assentamentos pode ser castrado na sua busca por sustentabilidade (SILVA e FERRANTE, 2009b, p.84).
}

A rediscussão do conceito de patrimonialidade ambiental aqui apresentada tem a força de uma proposta de novas investigações quais sejam: uma no âmbito da gestão; outra, com foco na educação. Em ambas, a questão ambiental permanece fulcral. 
A política educacional do campo está articulada à expectativa da sustentabilidade, estabelecida pelos governos mundiais. E esta sustentabilidade, enquanto conceito está diretamente relacionada com a patrimonialidade, no sentido de que, deve haver uma preocupação das gerações atuais com respeito ao meio ambiente, quanto ao que deixar às futuras gerações. O conceito de sustentabilidade a que se refere como sinônimo de patrimonialidade vem de Ribas; Severo; Miguel (2007):

\begin{abstract}
Sustentabilidade refere-se ao uso dos recursos biofísicos, econômicos e sociais, segundo sua capacidade em um espaço geográfico, para obter bens e serviços diretos e indiretos da agricultura e dos recursos naturais para satisfazer as necessidades das gerações futuras e presentes. $O$ valor presente dos bens e serviços deve representar mais que o valor das externalidades e dos insumos incorporados, melhorando ou pelo menos mantendo de forma indefinida a produtividade do ambiente biofísico e social. Além disso, o valor presente deve estar equitativamente distribuído entre os participantes do processo (RIBAS; SEVERO; MIGUEL, 2007, p 5).
\end{abstract}

Patrimonialidade, portanto, não diz respeito apenas ao direito das gerações futuras de usufruir dos recursos naturais, mas, sobretudo e, urgentemente, diz respeito às ações de todos os atores do assentamento rural e suas instituições, atreladas à questão da luta pela conquista da terra e do sentimento de pertencimento (Silva e Ferrante, 2009 a, 2009b).

Reitera-se assim o papel que ainda é fundamental para a escola do campo: o de formar as mentes e os corpos para a identidade rural, a questão da co-gestão do território, em que o crivo para as ações é o meio ambiente.

No que tange à política educacional do campo, dentro do que se afirma neste encaminhamento que não é final, não basta uma agenda política, é preciso uma ação transformadora da realidade, que exige dos agentes um conjunto de ações, atitudes e estratégias para uma efetiva patrimonialidade ambiental que contemple todas as dimensões sociais e humanas, econômicas e políticas; dimensões estas, permeadas pelos conceitos e ações de meio ambiente e sustentabilidade.

\title{
REFERÊNCIAS
}

ARROYO, M.G. A escola e o movimento social: relativizando a escola. ANDE, São Paulo, n. 12, p. 16-21, 1989.

ARROYO, M.G.; CALDART, R.S.; MOLINA, M.C. (Org.). Por uma educação do campo. Petrópolis: Vozes, 2004.

BIAZZO, P.P. Campo e rural, cidade e urbano: Distinções necessárias para uma perspectiva crítica em geografia agrária. In: ENCONTRO NACIONAL DE GRUPOS DE PESQUISA - ENGRUP. ,4 São Paulo, p. 132-150, 2008. Disponível em: < http://w3.ufsm.br/gpet/engrup/ivengrup/pdf/biazzo_p_p.pdf $>$ Acesso em 21 ago. 2015.

BRASIL. CONSELHO NACIONAL DE EDUCAÇÃO. Câmara de Educação Básica. Resolução nº 1 , de 3 de abril de 2002 a. Brasília. Institui Diretrizes Operacionais para a Educação Básica nas Escolas do Campo.

BRASIL. Ministério da Educação. Conselho Nacional de Educação. Câmara de Educação Básica. Resolução $\mathbf{n}^{\circ}$ 1, de 03 de abril de 2002. Institui Diretrizes Operacionais para a Educação Básica nas Escolas do Campo. 2002b. 
BRASIL. Educação do Campo: diferenças mudando paradigmas. Cadernos SECAD. Brasília, DF: MEC/SECAD, 2007.

BRASIL. Referências para uma política nacional de educação do campo. Caderno de Subsídios. Grupo Permanente de Trabalho de Educação do Campo. Brasília: MEC, 2003.

CALDART, R.S. Pedagogia do Movimento Sem-Terra. Petrópolis: Vozes, 2000.

CAPRA, F. A teia da vida. Uma nova compreensão científica dos sistemas vivos. São Paulo: Editora Cultrix, 1996.

EHLERS, E. M. Agricultura Sustentável: origens e perspectivas de um novo paradigma. São Paulo: Livros da Terra, 1996.

FERNANDES, B.M. Diretrizes de uma caminhada. In: ARROYO, M.G; CALDART, R.S.; MOLINA, M.C. Por uma educação do campo. Petrópolis: Vozes, 2004. p. 133-145.

JOLLIVET, M.; PAVÊ, A. O meio Ambiente: questões e Perspectivas para a pesquisa. In: VIEIRA, P.F e WEBER, J.S (org.) Gestão de recursos Naturais renováveis e Desenvolvimento: Novos desafios para a pesquisa ambiental. São Paulo, Ed. Cortez, 2000, p. 360-389.

OLlagnON, H. Estratégia Patrimonial Para a Gestão dos Recursos e dos Meio Naturais. Enfoque integrado da gestão do meio rural. In: VIEIRA, P.F.; WEBER, J. (orgs) Gestão de recursos naturais renováveis e desenvolvimento. Novos desafios para a pesquisa ambiental. 2.ed. São Paulo: Editora Cortez, 2000, p. 171-200.

PROJETO POLÍTICO PEDAGÓGICO. (2010-2012). Secretaria de Educação e Cultura. EMEF "Professora Maria de Lourdes da Silva Prado": 10 anos plantando sementes! Araraquara, Assentamento Monte Alegre VI., 2012.

RIBAS, R.P. SEVERO, C.M. MIGUEL, L.A. Agricultura familiar, extrativismo e sustentabiliade: o caso dos "samambaieiros" do litoral norte do Rio Grande do Sul. Revista de Economia e Sociologia Rural, Brasilia, v. 45, n. 1, jan./mar., 2007.

RODRIGUES, S.C.C. SANTANA, V.N.S. BERNABÉ, V.L. (orgs.). Educação, ambiente e sociedade: novas ideias e práticas em debate. Serra: CST - Companhia Siderurgica de Tubarão, 2007.

SAMPIERI, R. COLlADO, C. F. LUCIO, P. B. Metodologia de Pesquisa. 3. ed, São Paulo: McGraw Hill, 2006.

SCHNEIDER, S . Território, Ruralidade e Desenvolvimento. In: VELÁSQUEZ L. F. MEDINA, J. G. Ferro. (Orgs.). Las Configuraciones de los Territorios Rurales en el Siglo XXI. 1 ed. Bogotá/Colombia: Editorial Pontifícia Universidad Javeriana, 2009, 1, p. 67-108. Disponível em: < http://www.gbv.de/dms/ sub-hamburg/644775556.pdf>. Acesso em: 21 ago. 2015. 
SHIROMA, E.O. MORAES, M.C.M. EVANGELISTA, O. Política Educacional. 4. ed. Rio de Janeiro: Lamparina, 2007.

SILVA, C.R.; FERRANTE, V.L.S.B. Indicadores de gestão e educação: subsídios à patrimonialidade ambiental em assentamentos. Araraquara, SP: Revista UNIARA. N. 12, 2009 a.

SILVA, C.R.; FERRANTE, V.L.S.B. Patrimonialidade ambiental e pertencimento em assentamentos rurais. Reflexões e indicadores de pesquisa. Cadernos CERU/USP, São Paulo, SP, v. 20, série 2, 2009 b.

SILVA, C.R.; FERRANTE, V.L.S.B. Patrimonialidade e temática ambiental nos assentamentos: reflexões na busca de um modelo de desenvolvimento sustentável. In: CONGRESSO LATINO AMERICANO DE SOCIOLOGIA RURAL.,8, 2010. Porto de Galinhas. Anais...Porto de Galinhas, PE, 2010.

SILVA, C.R. Formação ambiental na escola do campo: uma análise documental sob o olhar do ecoletramento. 2011. 130f. (Dissertação-Mestrado). Programa de Pós Graduação em Educação. São Carlos: Universidade Federal de São Carlos, UFSCar, 2011.

SOUZA, M.A. Educação do campo: políticas, práticas pedagógicas e produção científica. Educação e Sociedade. Campinas, v.. 29, n. 105, p. 1089-1111, set./dez. 2008.

SOUZA, O.T. BRANDENBURG, A. Mudanças na relação sociedade e natureza e ação de políticas públicas de desenvolvimento rural na Região Metropolitana de Curitiba. In: CONGRESSO BRASILEIRO DE SOCIOLOGIA, 16, 2009, Rio de Janeiro. Anais...GT - Sociedade e ambiente, Rio de Janeiro, 2009.

SOUZA, A.I. et. al. Paulo Freire. Vida e obra. São Paulo: Expressão Popular, 2001.

VIEIRA, P.F e WEBER, J.S (org.) Gestão de recursos Naturais renováveis e Desenvolvimento: Novos desafios para a pesquisa ambiental. São Paulo, Cortez, 2000.

WHITAKER, D.C.A. Reforma agrária e meio ambiente: superando preconceitos contra o rural. In: Retratos de Assentamentos. Araraquara, n. 12, p. 33-46, 2009. 